\title{
Climate Change Highlights a Potentially Dangerous Trade-off
}

\section{Gonzalo González PhD}

In Cuba, as elsewhere, environmental issues derive from complex interactions among nature, society, the economy and politics. A multisector approach is needed to address them, in which the health and education systems are key, due to their role in alerting both the public and the authorities to potential risks.

As identified in 2012 by the Ministry of Science, Technology and the Environment, the main environmental problems faced by Cuba are soil degradation, forest coverage, contamination (from liquid and solid wastes, atmospheric emissions, noise, chemical products and dangerous dumping), loss of biological diversity, shortages and difficulties related to water availability and quality, and the impact of climate change.

Undoubtedly today climate change is one of the gravest concerns globally, including higher atmospheric temperatures, fusion of polar icecaps and mountains, elevated sea levels and shifting of climate zones north or south. Several of these aspects contribute to changes in vector profiles or the course and propagation of illnesses such as malaria, cholera, dengue and leishmaniasis. In particular, ambient conditions for survival and reproduction of pathogenic vectors and insects are more favorable under current conditions.

Additionally, local meteorological patterns have become more unstable and less predictable. The incidence of severe meteorological events is frequent, especially tropical hurricanes. These are associated with unintentional injuries, fatalities and post-disaster outbreaks of infectious diseases. They offer case studies of the difficult, contradictory options decisionmakers must wrestle with in resource-constrained settings such as those of Cuba and other developing countries, while providing them opportunities to arrive at innovative and economical solutions.

For example, Cuba's Civil Defense does an outstanding job of protecting people from hurricanes and other disasters, resulting in minimal loss of life. However, significant damages are always reported, and the housing stock-with over half of Cuban homes categorized as in fair or poor condition-is ill prepared to withstand high winds and torrential rains.

Although attempts are made to relocate affected families or rebuild their homes with sturdier materials, urgency and lack of financial resources have meant resorting to the least expensive and quickest way to put a roof over their heads: using fibrocement sheeting, whose price is one fifth that of metal sheeting, with equivalent time and ease of installation. The same factors have led authorities to purchase fibrocement sheeting to resolve roofing for other kinds of buildings in the wake of hurricanes.

But there is one problem: fibrocement contains asbestos fibers. The most dangerous form, amphibole asbestos, is banned in Cuba, but even the less hazardous chrysotile asbestos used here poses health risks. These are proportionate to concentration in the air, duration and frequency of exposure, size of fibers inhaled and time transpired from initial exposure. The smallest fibers penetrate airways, the rest expelled through sputum or saliva. When fibers reach the pulmonary interstitia, they are engulfed by macrophages, forming granulomas; fibers $>10 \mu \mathrm{m}$ are covered with iron-rich proteins, creating the socalled ferruginous or asbestos bodies, whose presence suggests important past asbestos exposure.[1]

The most frequent diseases related to asbestos inhalation are: asbestosis (asbestos-related pulmonary fibrosis), lung cancer and mesothelioma (pleural or peritoneal); there is inconsistent evidence that it increases risk of some nonrespiratory cancers as well.[2]

In Cuba, we have no data on asbestos-related deaths per se, but we have observed a rise in cancer deaths and in cancer death rates; cancer has overtaken heart disease as the number one cause of death in Cuba. Among cancer deaths in both sexes, malignant tumors of the trachea, bronchia and lung occupy first place, responsible for 3296 deaths in 2013.[3]

The latency period for asbestos-related illnesses is generally 20-40 years. In fact, European studies show elevated cancer rates in people exposed to asbestos fibers, despite the prohibition of asbestos use years ago. Asbestos fibers cannot be inhaled while they are locked in asbestos-containing construction materials, but if the structural integrity of the material is disturbed-in renovation, demolition or disaster-they can be released into the air. And of course, there is occupational exposure in workers who produce and install the fibrocement panels.[2]

In Cuba, while high rates of smoking and their relation to cancer are well documented, I am suggesting it would also be fundamental to pursue two lines of research: first, to determine the history of asbestos exposure in the rising numbers of cancer victims. And second, to research alternatives to the emergency roofing materials now being widely used in posthurricane reconstruction.

For example, internationally, there are experiences that substitute asbestos fibers with rice husk ash and sugar cane bagasse, low-cost residual products innocuous to human health. These may in fact provide a viable option for Cuba and deserve exploration.

While investigators in universities and research centers explore such ecologically safe production, and until the authorities have usable results for decisionmaking, it is still up to the health and education systems to play a more active role, publicizing the dangers of asbestos and asbestoscontaining products (including the danger of disturbing such materials), as well as the characteristics of associated diseases. 


\section{Viewpoint}

The case of asbestos roofing panels is one example of the potential danger of solving urgent social problems in the short term with measures that may lead to deadly threats to health in the longer term. -1 -

1. Hueto J, Almudevar E. Análisis y detección de fibras en tejido pulmonar. Anales Sistema Sanitario Navarra. 2005;28(Suppl 1). Spanish.

2. Agency for Toxic Substances and Disease Registry [Internet]. Atlanta: Centers for Disease Control and Prevention (US); c2015. Asbestos. Health effects: 2008 Apr [cited 2015 Jan 25]; [about 4 screens]. Available from: http://www .atsdr.cdc.gov/asbestos/asbestos/health_effects/
3. National Health Statistics and Medical Records Division (CU). Anuario Estadístico de Salud 2013. Havana: Ministry of Public Health (CU); 2014 Apr. 205 p. Spanish

Submitted: July 30, 2014

Approved for publication: April 5, 2015

Disclosures: None

Correspondence: gonzalog@ucp.vc.rimed.cu

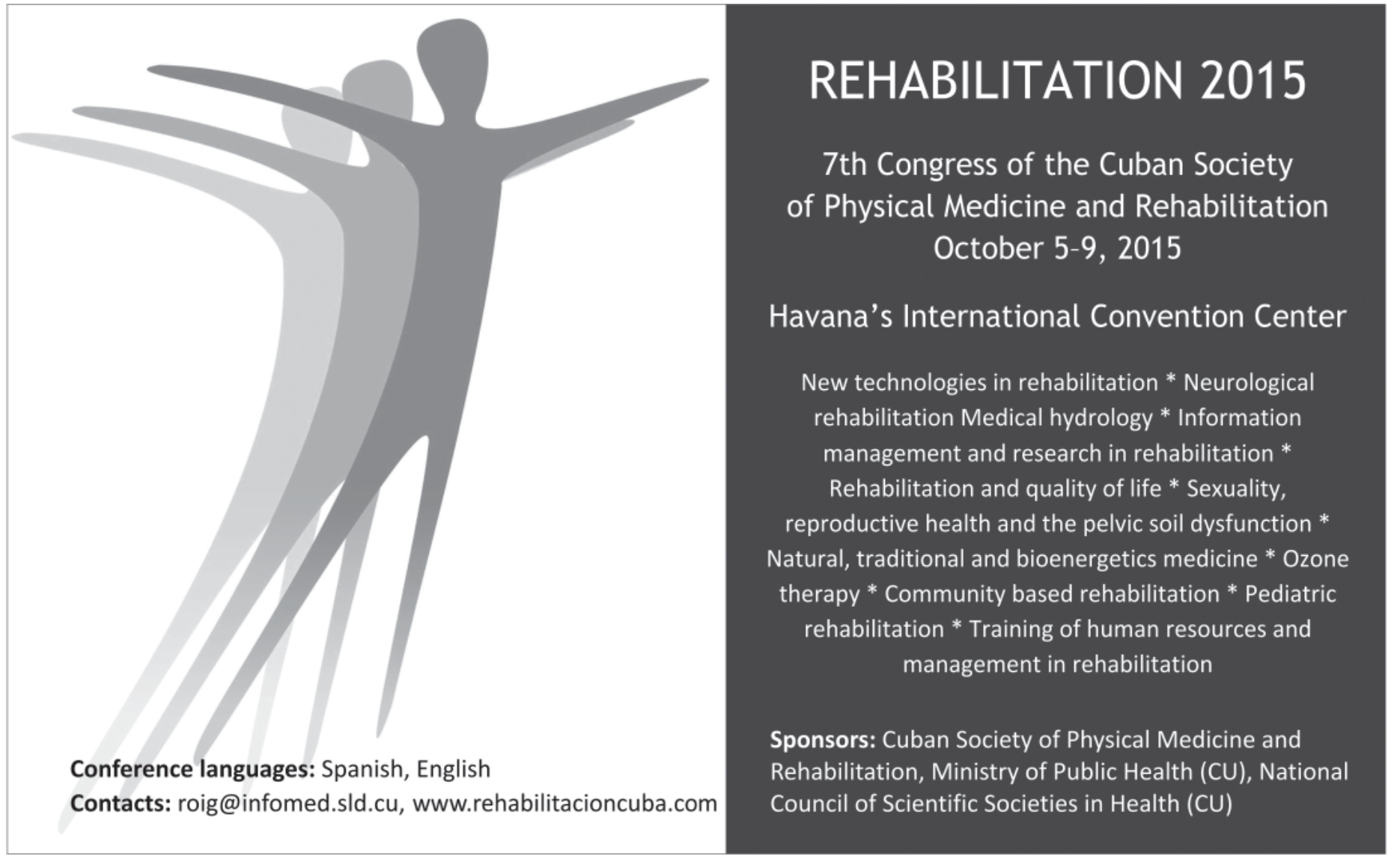

